\title{
An Asset and Liability Management (ALM) Model Using Integrated Chance Constraints
}

\author{
Siti Aida Sheikh Hussin ${ }^{\mathrm{a}}$, Gautam Mitra ${ }^{\mathrm{b}}$ and Diana Roman ${ }^{\mathrm{c}}$ \\ ${ }^{a}$ Statistics and Decision Sciences Department, Faculty of Computer and Mathematical Sciences, \\ Universiti Teknologi MARA Malaysia (UiTM), 40450 Shah Alam, Selangor Darul Ehsan, Malaysia \\ ${ }^{b, c}$ The Centre for the Analysis of Risk and Optimisation Modelling (CARISMA) \\ Brunel University London
}

\begin{abstract}
This paper discusses and develops a Two Stage Integrated Chance Constraints Programming for the Employees Provident Fund Malaysia. The main aim is to manage, that is, balance assets and liabilities. Integrated Chance Constraints not only limit the event of underfunding but also the amount of underfunding. This paper includes the numerical illustration.
\end{abstract}

Keywords:Employees Provident Fund, Stochastic Optimisation, Integrated Chance constraints, Asset \& Liability Management

PACS: $02.50 . \mathrm{Fz}$

\section{INTRODUCTION}

Asset and Liability Management (ALM) is a mathematical tool that is used to address the integrated management of assets as well as liabilities of pension funds, insurance products, bank loan bookkeeping and Hedge funds [1], [2] and [3]. ALM models also have been created for University Endowment Funds [4] and wealthy individuals [5] and [6]. ALM modelling is one of the active topics of research in the stochastic programming (SP) field. According to [7], the benefits of SP is the ability to support the asset and liability management as well as the risk management decisions in diverse situations and reflect the objectives and constraints of the users.

Stochastic Programming (SP) models are frequently used in the field of optimisation and operations research for various applications and industries settings. When SP models applied to ex-ante decision making problems, a decision must be made prior to the data which determine the model parameters evolve over time are revealed. For example, investment decisions on asset allocation and planning problems must be solved before future realisation of assets performance can be observed. The goal of SP models is to find the best decision that is attainable for all the pertinent data instances and maximises the expectation of certain function of the decision variables and thestochastic variables. Uncertainties are indexed over the scenario dimension, which connects the data vector to the scenario tree structure.

In SP formulation, $(\Omega, \mathrm{F}, \mathrm{P})$ symbolises the probability space, $\omega \in \Omega$ represents a realisation of the uncertainties, $\mathrm{p}(\omega)$, denotes the probability and $\mathrm{F}$ is the sigma space.Equation (1) represents the realisations for a given $\omega$.

$$
(A, b, c)_{\omega}=\xi_{\omega} \quad \text { or } \quad \xi(\omega)
$$

The canonical formulation of SP can be represented as :

$$
\min f_{0}(x, \xi)
$$

Subject to

$$
f_{i}(x, \xi) \leq 0, i=1, \ldots, I
$$


TSP is the most frequently applied and studied SP mode is two stage stochastic programming (TSP)1.TSP model with recourse can be represented as:

$$
\begin{array}{cc}
Z=\min / \max & c x+E_{\omega} Q(x, \omega) \\
\text { subject to } \quad A x & =b \\
& x \geq 0,
\end{array}
$$

and

$$
\begin{array}{cc}
Q(x, \omega)= & \min f(\omega) y \\
\text { subject to } & D(\omega) y=d(\omega)+B(\omega) x \\
& y \geq 0 .
\end{array}
$$

Matrix $A$ and vector $b$ are deterministic. $Q(x, \omega)$ denotes the recourse function that is defined by Equation (5). $\mathrm{D}(\omega)$ is the recourse matrix or technology matrix, the right hand side $d(\omega)$. B $(\omega)$ represents the inter stage linking matrix and and $\mathrm{f}(\omega)$ is the objective function coefficiens. The recourse action $\mathrm{y}(\omega)$ for a given realisation $\omega$ is obtained by solving Equation (5).

Two-stage linear programs with recourse are an important class of models that incorporate uncertainty within an optimisation model. In formulating the stochastic model, firstly the decision maker identifies the "Here-and-Now" decision variables (for activities that can't be postponed) together with the deterministic parameters and then identifies the remaining decisions which are specified by recourse variables and related random parameters. The optimal first stage decision $x$ must be feasible for all scenarios $\omega \in \Omega$. The second stage decision compensates and adapts to different scenarios $\omega$ after the outcomes $\omega$ are observed. The solution of this model provides the optimum solution of all scenarios $\omega \in \Omega$.

\section{Integrated chance constraints Programming (ICCP)}

Another important class of stochastic programming models is represented by the chance constraint problems (CCP). However due to the computational difficulties associated with mixed integer programs CCP is only suitable for small models. According to [8] and [9] chance constraints are based on a qualitative risk concept; these constraints control the probability of violation in the model but do not include the amount by which they are violated. ICCP was introduced by Klein Haneveld. Integrated chance constraints (ICC) unlike CCP is a quantitative approach, that include the extent of constraint violation. Instead of including just a bound for the probability of violating the constraint, ICC also include the bounds where the expectation of a shortfall or a surplus that is generated as a result of constraint violation. This bound is denoted by the parameter $\beta$ associated with each individual integrated chance constraint. It should be non-negative but unlike the reliability parameter of chance constraints it can be greater than 1 .

We define individual ICCP based on [10] as:

$$
\mathbb{E}_{\omega}\left[\eta_{\mathrm{i}}(\mathrm{x}, \omega)^{-}\right] \leq \kappa_{\mathrm{i}}, \quad \kappa_{\mathrm{i}} \geq 0
$$

Joint CCP are defined as:

$$
\mathbb{E}_{\omega}\left[\max _{i \in I} \eta_{i}(x, \omega)^{-}\right] \leq \kappa, \kappa \geq 0
$$

$\kappa_{\mathrm{i}}$ and $\kappa$ is a user defined maximum allowed expected shortfall. 
The idea behind ICCP in ALM, is that not only the probability of underfunding is included but the amount of underfunding is also considered by introducing a new decision variable that measures the shortfall. ICCP is an alternative and perhaps an enhanced formulation of CCP and is more appropriate especially for ALM where the quantitative value of shortfall, that is the amount of underfunding, is important. The constraints of ICCP model (for ALM) are simple linear restrictions and do not need binary variables.

\section{Employees Provident Fund (EPF) Malaysia}

This research concentrates on the EPF of Malaysia which is a defined contribution (DC) pension fund. EPF is mandatory for the formal private sector employees. Total accumulated assets including inactive members as at 2010 were recorded in Ringgit Malaysia (RM) 440.5 billion ( $£ 88.1$ billion). On the $31^{\text {st }}$ of December 2002 , the EPF was the 20th largest pension fund in the world and ranked as the eighth largest pension fund in Asia [11].

The main objective of EPF Malaysia is to provide for post-retirement securities through monthly compulsory saving for participants. The EPF was governed by the Employees Provident Fund Act, 1951, that was later replaced by the Employees Provident Fund Act, 1991. As of the end of 2010, the mandated contribution rate is within the range between $8 \%$ (minimum) to $11 \%$ of each member's monthly salary, while employers are obligated to contribute another $12 \%$ of an employee's salary to top up the members' savings.

EPF members' savings consist of two accounts. The first account, Account I, contains $70 \%$ of the members' monthly contribution, while the second account, Account II, stores 30\%. Account I is for retirement; withdrawals from this account are restricted to a member that reaches the retirement age (55 years old), is deformed, leaves the country or passes away. Pre-retirement withdrawals from savings from Account II are permitted for active participants subject to the country's laws in respect of EPF.

Over the years, other benefits beside retirement were added for participants. Active participants are allowed to withdraw for purposes like home ownership, children's education and health care. The EPF can only invest in assets as stated in the EPF Act 1991. EPF invests in five instruments; Malaysian Government Securities (MGS), loans and bonds, equities, properties and money market instruments (MMI).

$\mathrm{EPF}$, need to make dynamic decisions with multiple goals in order to satisfy stakeholders in term of regulations, investments, risk, etc. and at the same time ensure that the decisions implemented would not be detrimental to the economy of the country and the personal welfare of participants. One important aspect of the pension fund is the management of the investment allocation. Long term sufficient investment returns are needed to cope with liabilities and at the same time maintain its working capital adequately. Refer to [13] and [14] for more information pertaining to EPF, Malaysia.

\section{METHODOLOGY}

In this research, we formulate an ALM model using ICCP as a tool in the decision making process applied to EPF Malaysia.

Uncertainties impinge on both assets and liabilities in our ALM models. Data on the actual values of the stochastic parameters are disclosed in stages, and the decisions at every stage depends on the observations at that particular time, not on the future realizations. These uncertainties are captured using discrete models of randomness known as scenario generation.

The uncertainties which we model (data) for our model are:

i. Assets future returns, these are captured using Vector Autoregressive (VAR) scenario generation method.

ii. A population model to quantify the future population of EPF participants.

iii. Salary growth to define the future salary of the active participants based on age group.

iv. Contributions made by the participants. Contributions are calculated by combining the salary of active participants, the population currently holding the status as active participants in EPF as well as the monthly contribution rate.

v. Lump sum liabilities (lump sum payments for active as well as inactive participants at retirement, and lump sum payments to next of kin upon death).

vi. Pre-retirement withdrawals for active participants.

Refer to [15] on how the scenarios were generated. 


\section{Data Source}

At the initial time period the data are taken from the EPF 2010 annual report.The data used for the asset returns, cash flows, liabilities, pre-retirement liabilities are the value of the scenarios generated.

\section{Model Components}

The objective function is maximizing the expected terminal wealth.

\section{Objective Function}

$$
\operatorname{Maximize} \sum_{s=1}^{S} W_{T}^{s} \times \pi_{s} \quad \text { (Expected terminal wealth) }
$$

\section{The model indices:}

$\begin{array}{lll}i & \text { Assets } & \mathrm{i}=1, \ldots, \mathrm{I}, \mathrm{I}=5 \\ t & \text { Time period } & \mathrm{t}=1, \ldots, \mathrm{T}, \mathrm{T}=45 \\ \mathrm{~s} & \text { Scenarios } & \mathrm{s}=1, \ldots, \mathrm{S}, \mathrm{S}=2000\end{array}$
$\mathrm{S}=2000$.

We generate scenarios using the model mentioned earlier. For this study we have used 2000 scenarios that is,

\section{The parameters:}

$V_{t}^{s}$

$\pi_{s}$

$r_{i, t}^{s}$

$r l_{t}^{s}$

$r b_{t}^{s}$

$L_{t}^{s}$

$x_{i 0}$

$\alpha$

$l_{i}$

$u_{i}$

$G$
Contribution at time $t$ under scenario $s$

Probability of scenario s occurring (fixed at $1 / \mathrm{S}$ )

Uncertain Return of asset $i$ at time $t$ under scenario $s$

Lending rate at time $t$ under scenario $s$

Borrowing rate at time $\mathrm{t}$ under scenario $\mathrm{s}$

Liabilities at time t, scenario $s$

Initial holding of each asset at initial time period

Transaction cost expressed as a fraction of asset value fixed at $2 \%$

Lower bound of asset class $i$ as a fraction of total asset portfolio

Upper bound of asset class i as a fraction of total asset portfolio

Growth dividend

The parameters that are affected by uncertainty are $L_{t}^{s} \pi_{s}, r l_{t}^{s}, r b_{t}^{s}$ and $r_{i, t}^{s}$

\section{Decision variables}

$\begin{array}{cl}W_{t}^{s} & \begin{array}{l}\text { Total wealth at time } \mathrm{t} \text { scenario s (depending on the parameter value } \mathrm{G}, \text { this can take } \\ \text { positive and negative value) }\end{array} \\ x_{i, t}^{s} \geq 0 & \begin{array}{l}\text { Amount of asset i held at time t scenario s } \\ B_{i, t}^{s} \geq 0\end{array} \\ S_{i, t}^{s} \geq 0 & \text { Amount of asset i bought at time t scenario s } \\ H_{t}^{s} \geq 0 & \text { Amount of asset i sold at time t scenario s } \\ O_{t}^{s} \geq 0 & \text { Asset value } \\ Q_{t}^{s} \geq 0 & \text { Amount of cash borrowed at time t scenario s } \\ \end{array}$




\section{Wealth Constraint}

$$
W_{t}^{S}=\sum_{i=1}^{I} x_{i, t}^{S}+Q_{t-1}^{S}\left(1+r l_{t}^{S}\right)-O_{t-1}^{S}\left(1+r b_{t}^{S}\right) \quad t=1, \ldots, T, s=1, \ldots, S
$$

The total value of wealth at time $t$ and scenario $s$ is given by the total asset held in the time period and the amount of cash lent paid back including the lending rate deducting the amount borrowed and the borrowing rate (in the event that borrowing is necessary). The lending rate at time t, scenario $s$ is equivalent to MMI's return at time $t$, scenario s minus 0.005 while the borrowing rate is equivalent to MMI's return at time $t$, scenario $s$ plus 0.005 .

\section{Asset holdings constraints}

$$
\begin{array}{cc}
x_{i, 1}^{s}=x_{i 0}+B_{i, 1}^{s}-S_{i, 1}^{s} & t=1 \\
x_{i, t}^{s}=x_{i, t-1}^{s}\left(1+r_{i, t}^{s}\right)+B_{i, t}^{s}-S_{i, t}^{s} & t \geq 2
\end{array}
$$

Asset holdings constraints rebalance the holding of assets over time. The amount of assets held is equal to the holding for each asset from the previous time period and its return, plus the amount bought and minus the amount sold. At time period one the asset held is equivalent to initial holding, plus the assets bought minus assets sold.

\section{Asset value}

$$
H_{t}^{s}=\sum_{i=1}^{I} x_{i t}^{s} \quad t=1, \ldots, T, s=1, \ldots, S
$$

\section{Cash balance constraints}

$\sum_{i=1}^{I}(1+\alpha) B_{i, 1}^{S}+Q_{1}^{S}+L_{1}^{S}=V_{1}^{S}+\sum_{i=1}^{I}(1-\alpha) S_{i, 1}^{S}+O_{1}^{S} \quad t=1$

$\sum_{i=1}^{I}(1+\alpha) B_{i, t}^{S}+Q_{t}^{S}-\left(1+r l_{t}^{S}\right) Q_{t-1}^{S}+L_{t}^{S}=V_{t}^{S}+\sum_{i=1}^{I}(1-\alpha) S_{i, t}^{S}+O_{t}^{S}-\left(1+r b_{t}^{S}\right) O_{t-1}^{S}$

$\sum_{i=1}^{I}(1+\alpha) B_{i, t}^{S}-\left(1+r l_{t}^{S}\right) Q_{t-1}^{S}+L_{t}^{S}=V_{t}^{S}+\sum_{i=1}^{I}(1-\alpha) S_{i, t}^{S}-\left(1+r b_{t}^{S}\right) O_{t-1}^{S}$

$t=2 \leq t \leq T-1$

$t=T$

The amount invested in the purchase of new assets plus the assets lent (reinvest spare cash) and all the liabilities is equal to the contribution income from participants plus any cash generated from assets sold including the amount of cash borrowed. The transaction costs are introduced in a simplified form, that is, $(1+\alpha)$ and $(1-\alpha)$ and $\alpha=2 \%$ for selling and buying of assets. Borrowing and lending are not allowed in the last time period.

\section{Short sales constraints}

$$
\begin{array}{ll}
S_{i, 1}^{s} \leq x_{i 0} & t=1, s=1, \ldots, S \\
S_{i, t}^{s} \leq x_{i, t-1}^{s} & t \geq 2, s=1, \ldots, S
\end{array}
$$

We do not consider short sales in this problem. Amount of assets sold must be less than the amount of assets held in the last time period. 


\section{Bound constraints}

$$
l_{i} H_{t}^{s} \leq x_{i, t}^{s} \leq u_{i} H_{t}^{s} \quad t=1 \ldots T, i=1, \ldots, I, s=1, \ldots, S
$$

The maximum and minimum bounds of portfolio weights of assets held are included in the model as a constraint.

\section{Non Anticipativity Constraints}

$$
\begin{array}{rlrl}
x_{i, 1}^{s} & =x_{i, 1}^{1} & s=2, \ldots, S \\
B_{i, 1}^{s}=B_{i, 1}^{1} & s=2, \ldots, S \\
S_{i, 1}^{s}=S_{i, 1}^{1} & s=2, \ldots, S
\end{array}
$$

Decision at any stage does not depend on the future attainment of the random occurrences but only the observed part of the scenario. Therefore, we include the non anticipativity or information constraints. The investment decisions at $\mathrm{t}=1$ are the first stage decision variables, the rest is recourse variance.

The constraints of ICCP model can be represented as:

$$
\begin{array}{r}
H_{t}^{s}-\gamma L_{t}^{s}+\text { shortage }_{t}^{s} \geq 0 \\
\pi_{s} \sum_{s=1}^{s} \operatorname{shortage}_{t}^{s} \leq \lambda \pi_{s} \sum_{s=1}^{s} L_{t}^{s}
\end{array}
$$

In Equation (21), we ensure the expected value of shortages to be equal to or less than a pre-specified $\lambda$ (small percentage), in our case $5 \%$ of liabilities, while maximising the terminal wealth.

$\gamma \quad$ Level of meeting liabilities. In this research this is fixed at 1.10 .

$\lambda_{t} \quad$ Maximum expected shortfall. Assumed to be equal to $5 \%$.

M Large number (e.g. maximum value the investment portfolio is likely to reach)

G $\quad$ Growth dividend

Non implementable stochastic decision variable

shortage $_{t}^{s} \geq 0 \quad$ Amount of underfunding at time t scenario s

\section{RESULTS}

Result of ICCP with the value of $\lambda=0.05$ and $\gamma=1.10$.

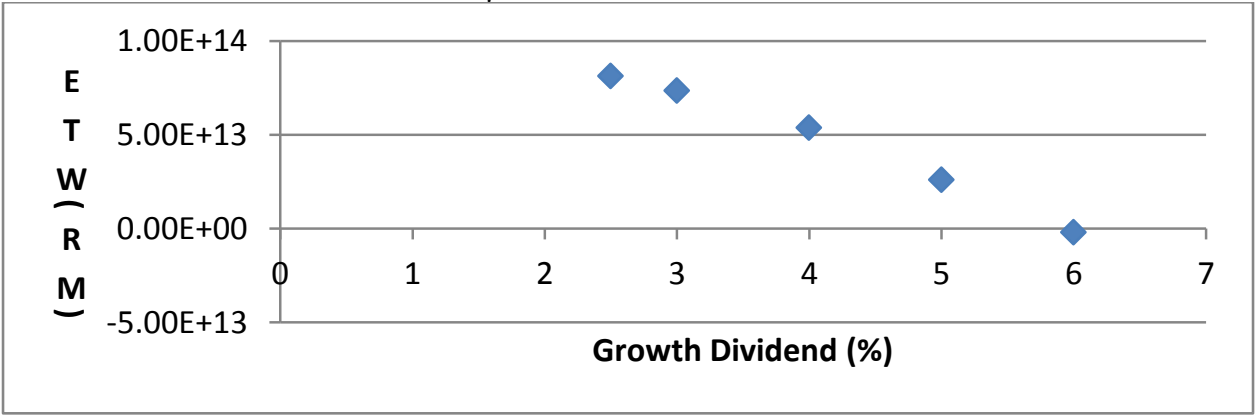

FIGURE 1. ICCP Model-Growth Dividend VS Expected Terminal Wealth (ETW) 
TABLE (1). ICCP Model -Growth Dividend VS Expected Terminal Wealth (ETW) and 1st stage Asset Allocation for Each Asset Class

\begin{tabular}{|c|c|c|c|c|c|c|}
\hline \multirow{2}{*}{$\begin{array}{c}\text { Growth } \\
\text { Dividend }\end{array}$} & \multirow{2}{*}{$\begin{array}{c}\text { ETW } \\
\boldsymbol{\%}\end{array}$} & \multicolumn{2}{|c|}{ Asset Allocation } \\
\cline { 3 - 7 } & $(\mathbf{R M})$ & MMI & MGS & EQT & MGS10 & PROP \\
\hline 2.5 & $8.11 \mathrm{E}+13$ & $3.17 \mathrm{E}+10$ & $1.19 \mathrm{E}+11$ & $1.11 \mathrm{E}+11$ & $1.62 \mathrm{E}+11$ & $2.11 \mathrm{E}+10$ \\
\hline & & 7.1 & 26.8 & 25.0 & 36.4 & 4.7 \\
\hline 3 & $7.35 \mathrm{E}+13$ & $3.21 \mathrm{E}+10$ & $1.19 \mathrm{E}+11$ & $1.11 \mathrm{E}+11$ & $1.62 \mathrm{E}+11$ & $2.11 \mathrm{E}+10$ \\
\hline & & 7.2 & 26.7 & 24.9 & 36.4 & 4.7 \\
\hline 4 & $5.35 \mathrm{E}+13$ & $3.30 \mathrm{E}+10$ & $1.19 \mathrm{E}+11$ & $1.11 \mathrm{E}+11$ & $1.62 \mathrm{E}+11$ & $2.11 \mathrm{E}+10$ \\
\hline & & 7.4 & 26.7 & 24.9 & 36.3 & 4.7 \\
\hline 5 & $2.58 \mathrm{E}+13$ & $3.44 \mathrm{E}+10$ & $1.19 \mathrm{E}+11$ & $1.11 \mathrm{E}+11$ & $1.60 \mathrm{E}+11$ & $2.11 \mathrm{E}+10$ \\
\hline & & 7.7 & 26.7 & 24.9 & 35.9 & 4.7 \\
\hline 6 & $-2.10 \mathrm{E}+12$ & $3.83 \mathrm{E}+10$ & $1.19 \mathrm{E}+11$ & $1.12 \mathrm{E}+11$ & $1.60 \mathrm{E}+11$ & $1.98 \mathrm{E}+10$ \\
\hline & & 8.5 & 26.5 & 24.9 & 35.6 & 4.4 \\
\hline
\end{tabular}

TABLE (2). ICCP Model-Maximum Expected Borrowing and Expected Borrowing at $\mathrm{t}=1$ VS Growth Dividend

\begin{tabular}{|c|c|c|}
\hline Dividend (\%) & $\begin{array}{c}\text { Maximum Expected } \\
\text { Borrowing (RM) }\end{array}$ & $\begin{array}{c}\text { Expected Borrowing at } \\
\mathbf{t = 1}(\mathbf{R M})\end{array}$ \\
\hline 2.5 & 0 & 0 \\
\hline 3 & 0 & 0 \\
\hline 4 & 0 & 0 \\
\hline 5 & $5.99 \mathrm{E}+11$ & 0 \\
\hline 6 & $1.41 \mathrm{E}+13$ & 0 \\
\hline
\end{tabular}

Table 1 shows that the highest asset held in the first time period for each promised dividend is the long term Malaysian Government Securities (MGS10). The expected wealth decreases as higher growth dividend is given to participants. In ICCP we imposed additional constraints requiring a match between assets and liabilities times $\gamma$ (weight of liabilities with respect to the asset value), causing the expected terminal wealth to be lower. Since we imposed an additional restriction, requiring that the expected shortage is less than 5\% of the total liabilities, the amount borrowed is high in ICCP. However, in the first time period, even at $6 \%$ guaranteed dividend, the liabilities are not funded by borrowing.

\section{CONCLUSION}

We have developed and presented a generic optimum decision model under uncertainty in particular the ICCP for the EPF Malaysia. This model is used to investigate different aspects of asset allocation and liability matching decisions. 


\section{REFERENCES}

1. W.T. Ziemba and J. Mulvey, World Wide Asset and Liability Modeling, United Kingdom: Cambridge University Press, 1998.

2. S. Zenios and W. Ziemba, Handbook of Asset and Liability Management Applications and case studies, North Holland, 2007.

3. G. Mitra and K. Schwaiger (eds.) Asset and Liability Management Handbook, Palgrave Macmillan, 2011.

4. R. C. Merton Optimal "Investment Strategies for University Endowment Funds" in Studies of Supply and Demand in Higher Education. University of Chicago Press, 1991, pp. $211-242$.

5. W. T. Ziemba, The Stochastic Programming Approach to Asset Liability and Wealth Management, CFA Institute, 2003.

6. $\quad$ E. Medova, J. K. Murphy, A.P. Owen, and K. Rehman, Quantitative Finance 8(6), 547-560 (2008).

7. J. Dupacova MMOR 50, 245-270 (1999).

8. W.K Klein Haneveld and M.H. Van der Vlerk, Computational Management Science 3(4), 245-269 (2006).

9. W. K Klein Haneveld, M. H. Streutker and M. H. Van der Vlerk, http://irs.ub.rug.nl/ppn/274795531.

10. K. Schwaiger, "Asset and Liability Management under Uncertainty: Models for Decision Making and Evaluation”, Ph.D. thesis, Brunel University London, 2009.

11. R. Ibrahim, in International Social Security Association 13th Regional Conference for Asia and The Pacific Kuwait, 810 March 2004.

12. Commisioner of Law Revision Malaysia Laws at Malaysia (reprint) ACT 452 Employees Provident Fund ACT 1991, Percetakan Nasional Malaysia Berhad, 2006.

13. S. A. Sheikh Hussin, G. Mitra, D. Roman, and W. Ahmad, Asset Liability Management Handbook, Basingstoke: Palgrave Macmillan, 2010, pp. 181-208.

14. Employees Provident Fund Malaysia, www.kwsp.gov.my.

15. S. A. Sheikh Hussin, "Employees Provident Fund (EPF) Malaysia Generic Models for Asset and Liability Management under Uncertainty”, Ph.D. thesis, Brunel University London, 2013. 